\title{
On the Beckmann Rearrangement of Ketoximes: A Kinetic Study in Trifluoromethanesulfonic Acid
}

\author{
N. C. MARZIANO, ${ }^{1}$ L. RONCHIN, ${ }^{1}$ C. TORTATO, ${ }^{1}$ O. TONON, ${ }^{2}$ R. BERTANI ${ }^{3}$ \\ ${ }^{1}$ Dipartimento di Chimica, Università di Venezia, Dorso Duro 2137, 30123 Venice, Italy \\ ${ }^{2}$ I.N.C.A., Consorzio Interuniversitario la Chimica per l'ambiente, Via della Libertà 5/12, 30175 Marghera-Venice, \\ Italy \\ ${ }^{3}$ Dipartimento Processi Chimici dell'Ingegneria e Centro Chimica Metallorganica, C.N.R., Facoltà di Ingegneria \\ Università di Padova Via Marzolo 9, 35131 Padua, Italy
}

Received 15 January 2004; accepted 21 February 2004

DOI 10.1002/kin.20011

Published online in Wiley InterScience (www.interscience.wiley.com).

\begin{abstract}
The formation and the destruction of an intermediate involved in the Beckmann rearrangement of 2,4,6-trimethylacetophenone oxime have been studied in concentrated trifluoromethanesulfonic acid by kinetic and spectroscopic measurements. Observed $\left(k_{\mathrm{obs}}\right)$ and thermodynamic rate constants $\left(k^{\circ}\right)$ have been estimated and the values compared with the ones obtained in perchloric, sulfuric, and methanesulfonic acids. In the range $80-100 \mathrm{wt} \%$ of sulfuric acid, combined analysis of $k_{\text {obs }}$ and $k^{\circ}$ rates shows a specific catalysis due to $\left[\mathrm{H}_{2} \mathrm{SO}_{4}\right]$ species. In trifluoromethanesulfonic acid, lower rate constants, compared to the values in sulfuric acid, have been observed which differ at $99 \mathrm{wt} \%$ by a factor of $10^{3} \mathrm{ca}$. The catalytic effect of different strong acids, the structure of the intermediate inferred from Raman and NMR spectra, and the role of the ion-pairs involved in the reaction are discussed. (C) 2004 Wiley Periodicals, Inc. Int J Chem Kinet 36: 417-426, 2004
\end{abstract}

\section{INTRODUCTION}

The conversion of ketoximes to amides has been widely studied on the attempt to understand the different features of the process known as "Beckmann rearrangement." The reaction is acid catalyzed under a variety

Correspondence to: N. C. Marziano; e-mail: marziano@unive.it. Contract grant sponsor: INCA (Interuniversity Consortium Chemistry for the Environment).

(c) 2004 Wiley Periodicals, Inc. of conditions and many mechanistic aspects of the reaction have long been firmly established [1-8]. Of particular interest from a practical point of view, but not exhaustively investigated, appears to be the rearrangement in aqueous sulfuric acid, where a large increase of rates has been observed in the range $80-100 \mathrm{wt} \%[6,7]$.

In the present paper the Beckmann rearrangement in trifluoromethanesulfonic acid (TFMSA or triflic acid) is tested by kinetic measurements and the rates compared with the ones already obtained in perchloric and sulfuric acids. Our interest in studying the process 
concerns some theoretical and practical topics, as well as the effects of the acid strength on the rates when different strong acids are compared. The results can help to distinguish whether the protonating ability of some particular acid systems, or a specific catalysis by sulfuric acid, or other causes are affecting the conversion reagents-products.

TFMSA has been chosen as suitable medium for comparison since it does not appear to be involved in the complex self-dissociation reactions observed in concentrated sulfuric acid [9]. TFMSA is also a strong monoprotic acid able to protonate between $80-100 \mathrm{wt} \%$ very weak bases as mesitylene, nitro-, and chloro-nitrobenzenes [10,11]. The 2,4,6,trimethylacetophenone oxime (TMTOX) has essentially been chosen as substrate for practical reasons. In this case the formation and the destruction of an intermediate, already observed in some of the previous studies carried out in perchloric and sulfuric acids [7], can be easily followed by kinetic measurements at $25^{\circ} \mathrm{C}$.

For a reliable discussion of the results in different acids, the rate constants referred to water as the standard state were estimated. The values were obtained by taking into account: (i) the effective concentrations of the reacting species involved in the rearrangement, (ii) the acidic properties of the medium described by "an activity coefficient function," and (iii) the interactions between solutes and solvents described by "the protonating ability" of the acid systems under investigation [11-14].

The final aim of the work is an extension of analogous studies over selected solid catalysts already tested in some acid catalyzed reactions [15-17]. Indeed, owing to the critical issues associated with the Beckmann rearrangement of ketoximes in aqueous strong acids or superacids, alternative reaction conditions supporting the need for more environmentally benign systems are continuously attempted.

\section{EXPERIMENTAL}

\section{Materials}

TMTOX was prepared by the method of Greer and Pearson [4]. Acetophenone oxime was prepared from the appropriate ketone, hydroxylamine hydrochloride, and sodium hydroxide in aqueous ethanol. The crude products were then purified by crystallization.

Aqueous solutions of triflic, methanesulfonic, and sulfuric acids were used as catalysts. The acid mixtures were prepared by diluting samples of TFMSA and methanesulfonic acid, both purified by vacuum distillation of the commercially available products, or by diluting Analar samples of sulfuric acid. The percent- age composition of the acids was selected by weighing and was checked by automatic potentiometric titration against standard solutions of $\mathrm{NaOH}$.

\section{Kinetic Studies}

The rearrangement of TMTOX was followed in a thermostatted cell at $25^{\circ} \mathrm{C}$ by measurements of the changes in the UV spectra of the acid solutions. Analysis of the spectral behaviour between 230 and $320 \mathrm{~nm}$ shows that at $310 \mathrm{~nm}$ the disappearance of oxime can be followed. At $235 \mathrm{~nm}$ and at $258 \mathrm{~nm}$, respectively, the formation and the destruction of an intermediate whose lifetime increases with increasing acidity can be tested. Indeed, the intermediate formed in concentrated acid solutions, where it is stable, can be converted to final product after dilution to the required acid concentration. Acidity ranges where the hydrolysis of the final product did not interfere with the rates of rearrangement were used. Concentrations of oxime were between $10^{-3}-10^{-4} \mathrm{M}$.

The first-order rate constants $\left(\log k_{\text {obs }}\right)$ obtained in TFMSA, sulfuric, and methanesulphonic acids between 10 and $60^{\circ} \mathrm{C}$ are reported in Table I together with the corresponding activation energies $\left(E_{\mathrm{a}}\right)$.

A comparison of the catalytic systems by a thermodynamic treatment of the rates was also attempted. In this analysis the concentration of the species (i.e. $\left.\log \left[\mathrm{H}^{+}\right], \log \left[\mathrm{H}_{2} \mathrm{O}\right]\right)$ of the respective acid solutions, the $\log \left[\mathrm{H}_{2} \mathrm{SO}_{4}\right]$ values available in sulfuric acid $>80$ wt $\%$, and the activity coefficient functions (or Mc functions) of the acidic mixtures under investigations [11-14] were used.

\section{Raman Measurements}

Raman spectra of 2,4,6-trimethyl- and unsubstituted acetophenone oximes in the range $86-96 \mathrm{wt} \%$ of sulfuric acid were performed in a quartz cell kept at $25^{\circ} \mathrm{C}$. The spectra were in the standard $90^{\circ}$ geometry using an argon-ion laser operating at $488 \mathrm{~nm}$, vertically polarized, and kept at constant power $(100 \mathrm{~mW})$. The scattered light with polarization parallel to that of the exciting beam was recorded. The signal was collected by a Jobin Yvon U 1000 double monochromator and analyzed by a photon-counting system. A resolution of $2 \mathrm{~cm}^{-1}$ was employed for all measurements. An extension of the measurements in concentrated aqueous solutions of triflic acid was also attempted. In this case a large unstructured background scattering was the main experimental difficulty observed [9]. It makes the spectral evaluations of triflic acid as solvent no longer reliable. 
Table I Beckmann Rearrangement of 2,4,6-Trimethyl Acetophenone Oxime in Aqueous $\mathrm{CF}_{3} \mathrm{SO}_{3} \mathrm{H}_{2} \mathrm{H}_{2} \mathrm{SO}_{4}$, and $\mathrm{CH}_{3} \mathrm{SO}_{3} \mathrm{H}$

\begin{tabular}{|c|c|c|c|c|c|c|c|c|}
\hline $\mathrm{CF}_{3} \mathrm{SO}_{3} \mathrm{H}(\% \mathrm{wt})$ & $T\left({ }^{\circ} \mathrm{C}\right)$ & $\log k\left(\sec ^{-1}\right)$ & $\mathrm{H}_{2} \mathrm{SO}_{4}(\% \mathrm{wt})$ & $T\left({ }^{\circ} \mathrm{C}\right)$ & $\log k\left(\sec ^{-1}\right)$ & $\mathrm{CH}_{3} \mathrm{SO}_{3} \mathrm{H}(\% \mathrm{wt})$ & $T\left({ }^{\circ} \mathrm{C}\right)$ & $\log k\left(\sec ^{-1}\right)$ \\
\hline \multicolumn{9}{|c|}{ (A) Formation of intermediate } \\
\hline 69.41 & 25 & -4.95 & 60.43 & 25 & -4.88 & 91.33 & 25 & -4.60 \\
\hline 69.41 & 40 & -3.94 & 60.43 & 40 & -4.05 & 96.32 & 25 & -4.40 \\
\hline 69.41 & 60 & -2.96 & 60.43 & 60 & -3.02 & 98.15 & 25 & -4.25 \\
\hline 73.12 & 25 & -4.79 & 78.09 & 25 & -3.97 & 100 & 25 & -4.18 \\
\hline 74.10 & 25 & -4.74 & 83.35 & 25 & -3.49 & & & \\
\hline 80.41 & 25 & -4.55 & 90.01 & 10 & -3.50 & & & \\
\hline 80.75 & 25 & -4.49 & 90.01 & 15 & -3.20 & & & \\
\hline 82.51 & 25 & -4.46 & 90.01 & 25 & -2.72 & & & \\
\hline 83.53 & 25 & -4.41 & 90.01 & 40 & -2.08 & & & \\
\hline 85.20 & 25 & -4.43 & 90.71 & 25 & -2.59 & & & \\
\hline 88.24 & 25 & -4.30 & & & & & & \\
\hline 93.77 & 25 & -4.31 & & & & & & \\
\hline 95.88 & 25 & -4.35 & & & & & & \\
\hline 98.43 & 25 & -4.43 & & & & & & \\
\hline 98.66 & 25 & -4.45 & & & & & & \\
\hline 99.10 & 25 & -4.47 & & & & & & \\
\hline 99.10 & 40 & -3.89 & & & & & & \\
\hline 99.10 & 60 & -3.02 & & & & & & \\
\hline \multicolumn{9}{|c|}{ (B) Destruction of intermediate } \\
\hline 83.10 & 25 & -2.88 & 78.09 & 25 & -2.79 & & & \\
\hline 83.94 & 25 & -3.20 & 83.35 & 25 & -3.70 & & & \\
\hline 86.60 & 25 & -3.78 & 87.9 & 25 & -4.48 & & & \\
\hline 88.84 & 25 & -4.45 & & & & & & \\
\hline
\end{tabular}

Activation energies $\left(E_{\mathrm{a}}\right)$ for the formation of an intermediate product: in $\mathrm{CF}_{3} \mathrm{SO}_{3} \mathrm{H}$ : at $69.41 \mathrm{wt} \%=25.2 \mathrm{kcal} \mathrm{mol}^{-1}$; at $99.1 \mathrm{wt} \%=18.8$ $\mathrm{kcal} \mathrm{mol}{ }^{-1}$; in $\mathrm{H}_{2} \mathrm{SO}_{4}$ : at $60.43 \mathrm{wt} \%=24.6 \mathrm{kcal} \mathrm{mol}^{-1}$; at $90.01 \mathrm{wt} \%=18.3 \mathrm{kcal} \mathrm{mol}^{-1}$.

\section{NMR Measurements}

The starting oximes in acetone-d and the species formed at suitable time when the oximes were dissolved in different acids have been studied by ${ }^{1} \mathrm{H}$ NMR, ${ }^{13} \mathrm{C}$ NMR, and ${ }^{15} \mathrm{~N}$ NMR spectroscopy. The spectra were recorded on two Brucker "Avance" spectrometers equipped with a variable-temperature probe and operating the first at $300.152\left({ }^{1} \mathrm{H} \mathrm{NMR}\right)$, at 75.480 $\left({ }^{13} \mathrm{C}\right.$ NMR $)$, and at $30.420\left({ }^{15} \mathrm{~N} \mathrm{NMR}\right)$ and the second at 400.13 and $100.61 \mathrm{MHz}$, respectively, for ${ }^{1} \mathrm{H}$ NMR, ${ }^{13} \mathrm{C}$ NMR.

Acetone-d (referred to TMS) in a coaxial tube as external reference was used in the analysis of the acid systems. Solutions and spectra of the oximes were performed at $25^{\circ} \mathrm{C}$ except for the TMTOX in sulfuric acid which was studied at $3^{\circ} \mathrm{C}$ ca. In these experimental conditions the fast change of the species with time can be easily followed.

The results and the species detected are reported in Table II. The assignments of the proton resonances were performed by standard chemical shift correlations and NOESY experiments. The ${ }^{13} \mathrm{C}$ resonances were attributed through 2D-heterocorrelated COSY experiments (HMQC with bird sequence [18] and quadrature along F1 achieved using the TPPI method [19] for the H-bonded carbon atoms, HMBC [20] for the quaternary ones).

\section{RESULTS AND DISCUSSION}

\section{Kinetic Behaviour of Oximes}

The acidic dependence of reaction rates in acid catalyzed reactions is a useful approach to test the behaviour of solutes and in Table I the new results obtained by following the rearrangement of TMTOX in different acids are reported. In Fig. 1 the observed rate constants $\left(\log k_{\mathrm{obs}}\right)$ of the oxime available in perchloric, sulfuric, and triflic acids are compared.

A first analysis of the results clearly shows that at low acidity ranges the rates exhibit a very similar trend and almost equal values. Conversely, a steep increase of rates is observed in sulfuric acid above $80 \mathrm{wt} \%$ where the kinetic data, compared to the values in TFMSA at $99 \mathrm{wt} \%$, differ by a factor of $10^{3} \mathrm{ca}$.

A gentle decrease of rates is also observed above 92 $\mathrm{wt} \%$ of triflic acid, where strong interactions between the ionic species and formation of ion-pairs can occur [9]. 
Table II ${ }^{1} \mathrm{H}$ NMR and ${ }^{13} \mathrm{C}$ NMR Data of 2,4,6-Trimethyl- and Acetophenon-Oximes a) Assignments ( $\delta$ Values in ppm from TMS)

\begin{tabular}{|c|c|c|}
\hline Compounds & ${ }^{1} \mathrm{H}$ Peaks & ${ }^{13}$ C Peaks \\
\hline I (in deuterated acetone) & $\begin{array}{l}\text { (a) } 2.16 \text {; (b) } 6.86 \text {; (c) } 2.25 \text {; } \\
\text { (d) } 2.07 \text {; (e) } 10.00\end{array}$ & $\begin{array}{l}\text { (1) } 134.76 ;(2,6) 136.15 ;(3,5) 128.71 ;(4) 138.11 ;(\alpha) 19.86 \text {; } \\
\text { (ß) } 21,44 ;(\gamma) 16.21 ;(\delta) 157.87\end{array}$ \\
\hline II (in $\mathrm{CF}_{3} \mathrm{SO}_{3} \mathrm{H}(99 \%)$ ) & $\begin{array}{l}\text { (a) } 2.23 \text {; (b) } 7.01 \text {; (c) } 2.34 \text {; } \\
\text { (d) } 2.76 \text {; (f) } 12.14\end{array}$ & $\begin{array}{l}\text { (1) } 126.12 ;(2,6) 136.35 ;(3,5) 130.75 ;(4) 145.03 ;(\alpha) 19.17 \text {; } \\
\text { (ß) } 20.30 ;(\gamma) 21.11 ;(\delta) 181.10\end{array}$ \\
\hline II (in $\mathrm{H}_{2} \mathrm{SO}_{4}(95 \%)$ ) & $\begin{array}{l}\text { (a) } 2.32 ; \text { (b) } 7.08 ; \text { (c) } 2.40 \text {; } \\
\text { (d) } 2.85 \text {; (f) } 12.00\end{array}$ & $\begin{array}{l}\text { (1) } 125.14 ;(2,6) 135.44 ;(3,5) 129.86 ;(4) 143.74 ;(\alpha) 18.74 \text {; } \\
\text { (ß) } 19.62 ;(\gamma) 20.95 ;(\delta) 178.58\end{array}$ \\
\hline II (in $\mathrm{CH}_{3} \mathrm{SO}_{3} \mathrm{H}(99 \%)$ ) & $\begin{array}{l}\text { (a) } 2.16 \text {; (b) } 6.97 \text {; (c) } 2.23 \text {; } \\
\text { (d) } 2.56 \text {; (f) } 12.56\end{array}$ & $\begin{array}{l}\text { (1) } 125.48 ;(2,6) 135.27 ;(3,5) 128.87 ;(4) 142.21 ;(\alpha) 18.24 \text {; } \\
\text { (ß) } 18.86 ;(\gamma) 20.20 ;(\delta) 175.44\end{array}$ \\
\hline $\mathrm{III}^{a}$ (in $\mathrm{CF}_{3} \mathrm{SO}_{3} \mathrm{H}(99 \%)$ ) & $\begin{array}{l}\text { (a) } 2.41 \text {; (b) } 7.06 \text {; (c) } 2.31 \text {; } \\
\text { (d) } 3.17\end{array}$ & $\begin{array}{l}\text { (1) } 118.76 ;(2,6) 139.20 ;(3,5) 131.05 ;(4) 147.43 ;(\alpha) 18.11 \text {; } \\
\text { (ß) } 21.53 ;(\gamma) 4.50 ;(\delta) 121.44\end{array}$ \\
\hline $\mathrm{III}^{a}\left(\right.$ in $\mathrm{H}_{2} \mathrm{SO}_{4}(95 \%)$ ) & $\begin{array}{l}\text { (a) } 2.52 \text {; (b) } 7.16 \text {; (c) } 2.43 \text {; } \\
\text { (d) } 3.33\end{array}$ & $\begin{array}{l}\text { (1) } 117.70 ;(2,6) 138.23 ;(3,5) 130.24 ;(4) 146.44 ;(\alpha) 17.75 ; \\
\text { (ß) } 21.33 ;(\gamma) 3.82 ;(\delta) 120.35\end{array}$ \\
\hline IV (in deuterated acetone) & $\begin{array}{l}\text { (a,c) } 7.37 \text {; (b) } 7.69 ; \text { (d) } 2.84 \\
\text { (e) } 10.29\end{array}$ & 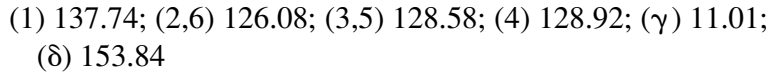 \\
\hline $\mathrm{V}^{b}\left(\right.$ in $\left.\mathrm{CF}_{3} \mathrm{SO}_{3} \mathrm{H}(99 \%)\right)$ & $\begin{array}{l}\text { (a) } 7.73 \text {; (b) } 7.61 \text {; (c) } 7.78 \text {; } \\
\text { (d) } 2.86 \text {; (f) } 11.62\end{array}$ & 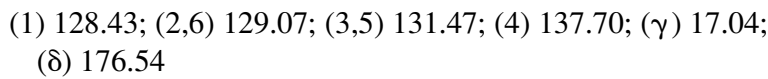 \\
\hline $\mathrm{V}^{b}\left(\right.$ in $\left.\mathrm{H}_{2} \mathrm{SO}_{4}(95 \%)\right)$ & $\begin{array}{l}\text { (a) } 7.79 ; \text { (b) } 7.70 \text {; (c) } 7.86 \text {; } \\
\text { (d) } 2.92 ; \text { (f) } 11.95\end{array}$ & 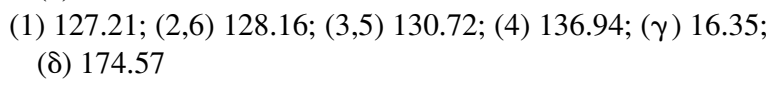 \\
\hline $\mathrm{V}^{b}\left(\right.$ in $\left.\mathrm{CH}_{3} \mathrm{SO}_{3} \mathrm{H}(99 \%)\right)$ & $\begin{array}{l}\text { (a,c) } 7.65 \text {; (b) } 7.52 \text {; (d) } 2.67 \text {; } \\
\text { (f) } 12.41\end{array}$ & $\begin{array}{l}\text { (1) } 127.82 ;(2,6) 128.28 ;(3,5) 129.98 ;(4) 135.41 ;(\gamma) 16.28 \text {; } \\
\text { (ठ) } 172.11\end{array}$ \\
\hline
\end{tabular}

${ }^{a}{ }^{15} \mathrm{~N}$ NMR data of nitrilium ion are: 144.63 in $\mathrm{CF}_{3} \mathrm{SO}_{3} \mathrm{H} ; 144.33$ in $\mathrm{H}_{2} \mathrm{SO}_{4}\left(\delta\right.$ values in ppm from aqueous $\mathrm{NH}_{4} \mathrm{NO}_{3}$ ).

${ }^{b}{ }^{15} \mathrm{~N}$ NMR data of N-protonated acetophenonoxime ( $\delta$ values in ppm from aqueous $\left.\mathrm{NH}_{4} \mathrm{NO}_{3}\right)$ are: $211.25 \mathrm{ppm}\left(J_{\mathrm{NH}}=108.18 \mathrm{~Hz}\right)$ in $\mathrm{CF}_{3} \mathrm{SO}_{3} \mathrm{H} ; 212.39\left(J_{\mathrm{NH}}=111.70 \mathrm{~Hz}\right)$ in $\mathrm{H}_{2} \mathrm{SO}_{4} ; 217.09\left(J_{\mathrm{NH}}=103.89 \mathrm{~Hz}\right)$ in $\mathrm{CH}_{3} \mathrm{SO}_{3} \mathrm{H}$.

b) Species Detected

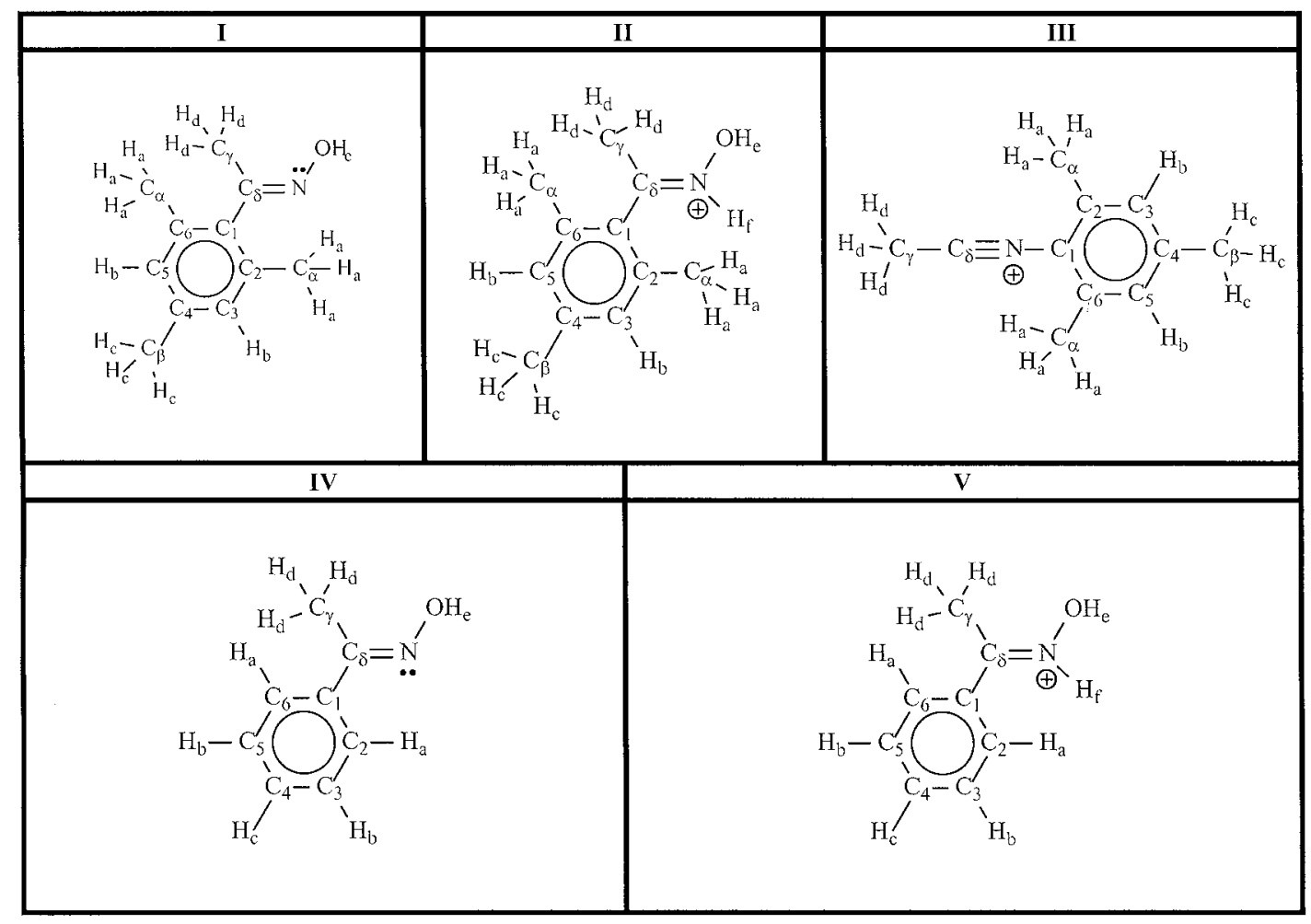




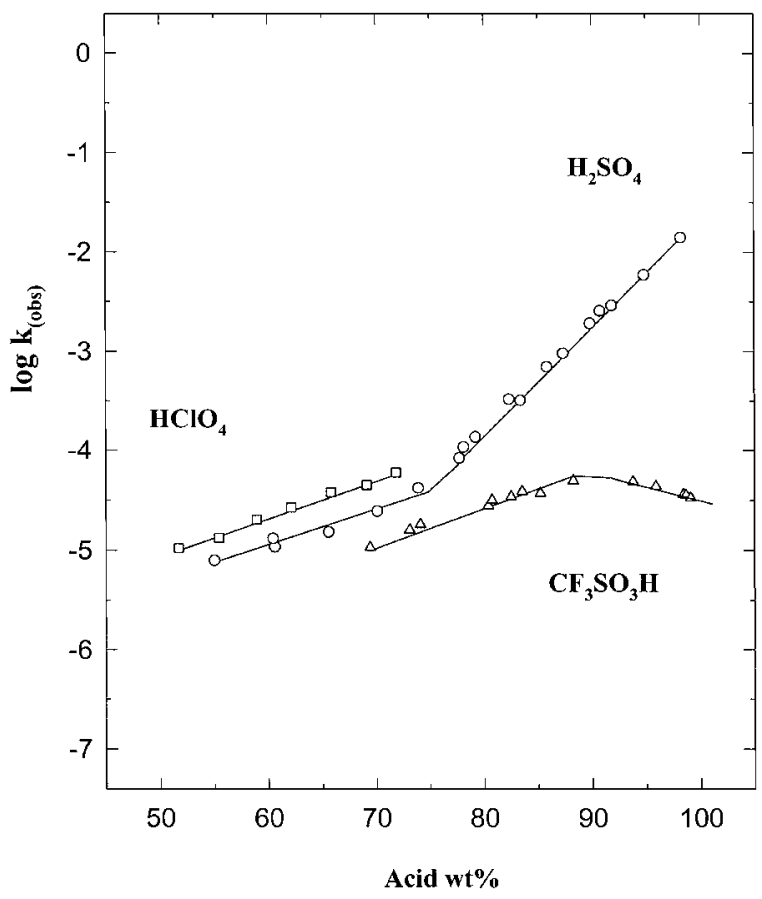

Figure 1 Beckmann rearrangement of 2,4,6-trimethylacetophenone oxime at $25^{\circ} \mathrm{C}$. Rate profiles ( $\log k_{\text {obs }}$ vs wt $\%$ ) for the formation of intermediate in $(\square) \mathrm{HClO}_{4},(\mathrm{O}) \mathrm{H}_{2} \mathrm{SO}_{4}$, and $(\Delta) \mathrm{CF}_{3} \mathrm{SO}_{3} \mathrm{H}$. Experimental data in $\mathrm{HClO}_{4}$ from Ref. [7]; in $\mathrm{H}_{2} \mathrm{SO}_{4}$ from Ref. [7] and present work; in $\mathrm{CF}_{3} \mathrm{SO}_{3} \mathrm{H}$ from present work.

The acidic dependence of rates was also analyzed by using the effective concentrations of solutes involved in the reaction and the acidic properties of perchloric, sulfuric, triflic, and methanesulfonic acids. The latter were evaluated by the "activity coefficient functions" as parameters related to variations of activity coefficients of the different acidic mixtures [11-14]. Indeed, a number of studies in concentrated aqueous solutions of strong acids (HA) applied both to dissociation of HA (equilibrium 1) and to protonation of weak bases (B) (equilibrium 2) shows that the activity coefficient terms of thermodynamic Eqs. (3) and (4) can practically be determined by an activity coefficient function of the solvent $(M c(s))$ or by an activity coefficient function of solutes $(M c(i))$. The functions defined, respectively, by Eqs. (5) and (6) and estimated by independent measurements of the equilibria (1) and (2) are found to be linearly related between them by the relationships ( 7 or $7^{\prime}$ )

$$
\begin{gathered}
\mathrm{HA} \rightleftharpoons \mathrm{H}^{+}+\mathrm{A}^{-} \\
\mathrm{B}+\mathrm{H}^{+} \rightleftharpoons \mathrm{BH}^{+} \\
\mathrm{p} K_{\mathrm{HA}}=\log [\mathrm{HA}] /\left[\mathrm{A}^{-}\right]-\log \left[\mathrm{H}^{+}\right] \\
-\log \left(f_{\mathrm{A}^{-}} f_{\mathrm{H}^{+}} / f_{\mathrm{HA}}\right)
\end{gathered}
$$

$$
\begin{gathered}
\mathrm{p} K_{\mathrm{BH}^{+}}=\log \left[\mathrm{BH}^{+}\right] /[\mathrm{B}]-\log \left[\mathrm{H}^{+}\right] \\
-\log \left(f_{\mathrm{B}} f_{\mathrm{H}^{+}} / f_{\mathrm{BH}^{+}}\right) \\
-\log \left(f_{\mathrm{A}^{-}} f_{\mathrm{H}^{+}} / f_{\mathrm{HA}}\right)=\operatorname{Mc}(\mathrm{s}) \\
-\log \left(f_{\mathrm{B}^{*}} f_{\mathrm{H}^{+}} / f_{\mathrm{B}^{*} \mathrm{H}^{+}}\right)=\operatorname{Mc}(\mathrm{i}) \\
-\log \left(f_{\mathrm{B}^{*}} f_{\mathrm{H}^{+}} / f_{\mathrm{B}^{*} \mathrm{H}^{+}}\right)=-n_{\mathrm{is}} \log \left(f_{\mathrm{A}^{-}} f_{\mathrm{H}^{+}} / f_{\mathrm{HA}}\right) \\
\operatorname{Mc}(\mathrm{i})=n_{\mathrm{is}} \mathrm{Mc}(\mathrm{s})
\end{gathered}
$$

In this treatment the Mc functions are a measure of the deviations from the ideality of the species involved in the acidic medium under investigation. The $n_{\text {is }}$ values are parameters related to the "protonating ability" of the solvent and can be interpreted as a measure of the specific interactions between solutes and solvents in the proton transfer process from $\left(\mathrm{H}^{+}\right)_{\mathrm{aq}} \mathrm{A}^{-}$to $\mathrm{BH}^{+}$ $\mathrm{A}^{-}$. Such a procedure, widely tested in the studies of equilibria [10-14] and reactivity $[14,21,22]$ allows to obtain a reliable description of a process in nonideal acid systems and rate constants $\left(k^{\circ}\right)$ referred to water as standard state, the latter to be used, especially, for comparing solutes in different acids.

The new results show the following points of interest:

i. The rearrangement of TMTOX in monoprotic acids can be described by the linear relationships obtained by plotting $\left\{\log k_{\mathrm{obs}}-\log \left[\mathrm{H}^{+}\right]+\right.$ $\left.\log \left[\mathrm{H}_{2} \mathrm{O}\right]\right\}$ versus the corresponding Mc functions (see Fig. 2a and 2b).

ii. The rearrangement of TMTOX in sulfuric acid (range 52-98 wt \%) can be described by the linear relationship obtained by plotting $\left\{\log k_{\mathrm{obs}}-\right.$ $\left.\log \left[\mathrm{H}^{+}\right]+\log \left[\mathrm{H}_{2} \mathrm{O}\right]-\log \left[\mathrm{H}_{2} \mathrm{SO}_{4}\right]\right\}$ versus $\mathrm{Mc}$, where $\left[\mathrm{H}_{2} \mathrm{SO}_{4}\right]$ are the concentrations of the molecular species determined by Raman measurements [13]. A comparison of the trend in Fig. 3a and $3 \mathrm{~b}$ clearly shows the progressive involvement of sulfuric acid as specific catalytic species of the reaction. Indeed, in the range $80-100 \mathrm{wt} \%$, the molecular species of sulfuric acid increases with the acid concentration according to equilibrium $\left[\mathrm{H}_{2} \mathrm{SO}_{4} \rightleftharpoons \mathrm{HSO}_{4}{ }^{-}+\mathrm{H}^{+}\right]$and the variation of $\left[\mathrm{H}_{2} \mathrm{SO}_{4}\right]$ becomes significant and experimentally available [13,14].

iii. A $\log k^{0}$ value $=-4.8$ has been estimated by the intercepts of the linear relationships observed in perchloric, methanesulfonic, triflic, and sulfuric acids.

iv. An extension of the Mc treatment is reported in Table III where TMTOX, cyclohexanone oxime, 

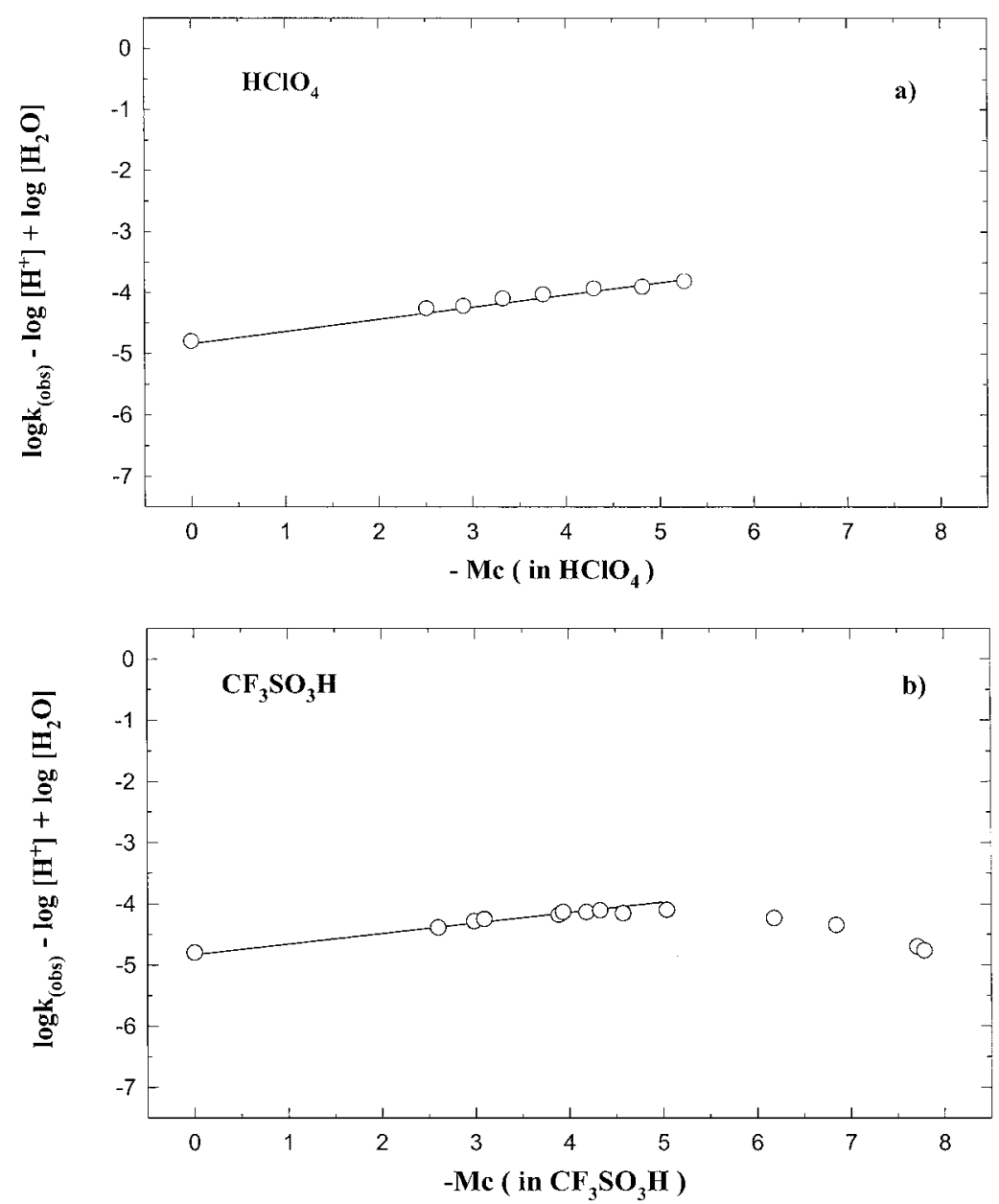

Figure 2 Beckmann rearrangement of 2,4,6-trimethylacetophenone oxime in $\mathrm{HClO}_{4}$ (range 52-72 wt $\%$ ) and in $\mathrm{CF}_{3} \mathrm{SO}_{3} \mathrm{H}$ (range $69-100 \mathrm{wt} \%$ ) at $25^{\circ} \mathrm{C}$ : a) Plot of $\left\{\log k_{\mathrm{obs}}-\log \left[\mathrm{H}^{+}\right]+\log \left[\mathrm{H}_{2} \mathrm{O}\right]\right\}$ vs $\mathrm{Mc}$ in $\mathrm{HClO}_{4}$; intercept $=-4.8$, slope $=0.2$. b) Plot of $\left\{\log k_{\mathrm{obs}}-\log \left[\mathrm{H}^{+}\right]+\log \left[\mathrm{H}_{2} \mathrm{O}\right]\right\}$ vs $\mathrm{Mc}_{\text {in }} \mathrm{CF}_{3} \mathrm{SO}_{3} \mathrm{H}$; (intercept $=-4.8$, slope $=0.18$ in the range 50-90 wt $\%$ ). Values of $\log k_{\mathrm{obs}}$ for the formation of intermediate in $\mathrm{HClO}_{4}$ from Ref. [7]; in $\mathrm{CF}_{3} \mathrm{SO}_{3} \mathrm{H}$ from present work. Values of $\mathrm{Mc}$ and $\log \left[\mathrm{H}^{+}\right.$] in $\mathrm{HClO}_{4}$ and in $\mathrm{CF}_{3} \mathrm{SO}_{3} \mathrm{H}$ from Ref. [11].

and substituents effects of some acetophenone oximes are compared by the $\log k^{0}$ values. The results were determined by the plots $\left\{\log k_{\mathrm{obs}}-\right.$ $\left.\log \left[\mathrm{H}^{+}\right]+\log \left[\mathrm{H}_{2} \mathrm{O}\right]\right\}$ versus $\mathrm{Mc}$ for kinetic data in $\mathrm{HClO}_{4}, \mathrm{CH}_{3} \mathrm{SO}_{3} \mathrm{H}, \mathrm{CF}_{3} \mathrm{SO}_{3} \mathrm{H}$, and $\mathrm{H}_{2} \mathrm{SO}_{4}<$ $80 \mathrm{wt} \%$ and by the plots $\left\{\log k_{\mathrm{obs}}-\log \left[\mathrm{H}^{+}\right]+\right.$ $\left.\log \left[\mathrm{H}_{2} \mathrm{O}\right]-\log \left[\mathrm{H}_{2} \mathrm{SO}_{4}\right]\right\}$ versus $\mathrm{Mc}$ for kinetic data in $\mathrm{H}_{2} \mathrm{SO}_{4}>80 \mathrm{wt} \%$.

The trend of meta- and para-substituted acetophenone oximes, analyzed by the relationship $\log k^{0}$ versus the Hammett $\sigma$ constants, shows a high sensitivity of the substituents to the rearrangement, with a slope value $(\rho)=-3.3$. In an analogous plot, a slope of -1.2 and serious deviations from linearity have been reported by using $\log k_{\text {obs }}$ values [7].

\section{Kinetic Behaviour of Intermediate}

Further experimental details of the rearrangement of TMTOX in triflic, perchloric, and sulfuric acids were obtained by following the destruction of the intermediate whose lifetime increases with the acid concentration. Analysis of the available reaction rates by the plots $\left\{\log k_{\text {obs }}(\right.$ intermediate $\left.)-\log \left[\mathrm{H}^{+}\right]+\log \left[\mathrm{H}_{2} \mathrm{O}\right]\right\}$ versus Mc shows slope values $=-1.75$ in $\mathrm{HClO}_{4},-1.75$ in $\mathrm{CF}_{3} \mathrm{SO}_{3} \mathrm{H},-1.32$ in $\mathrm{H}_{2} \mathrm{SO}_{4}$ against slope values of 0.2 ca. observed by following the disappearance of the starting oxime in the same acids. As expected, values of intercepts $(i=4.8)$ are estimated in any case.

Further results obtained by spectroscopic analysis of the intermediate are reported in the next section. 

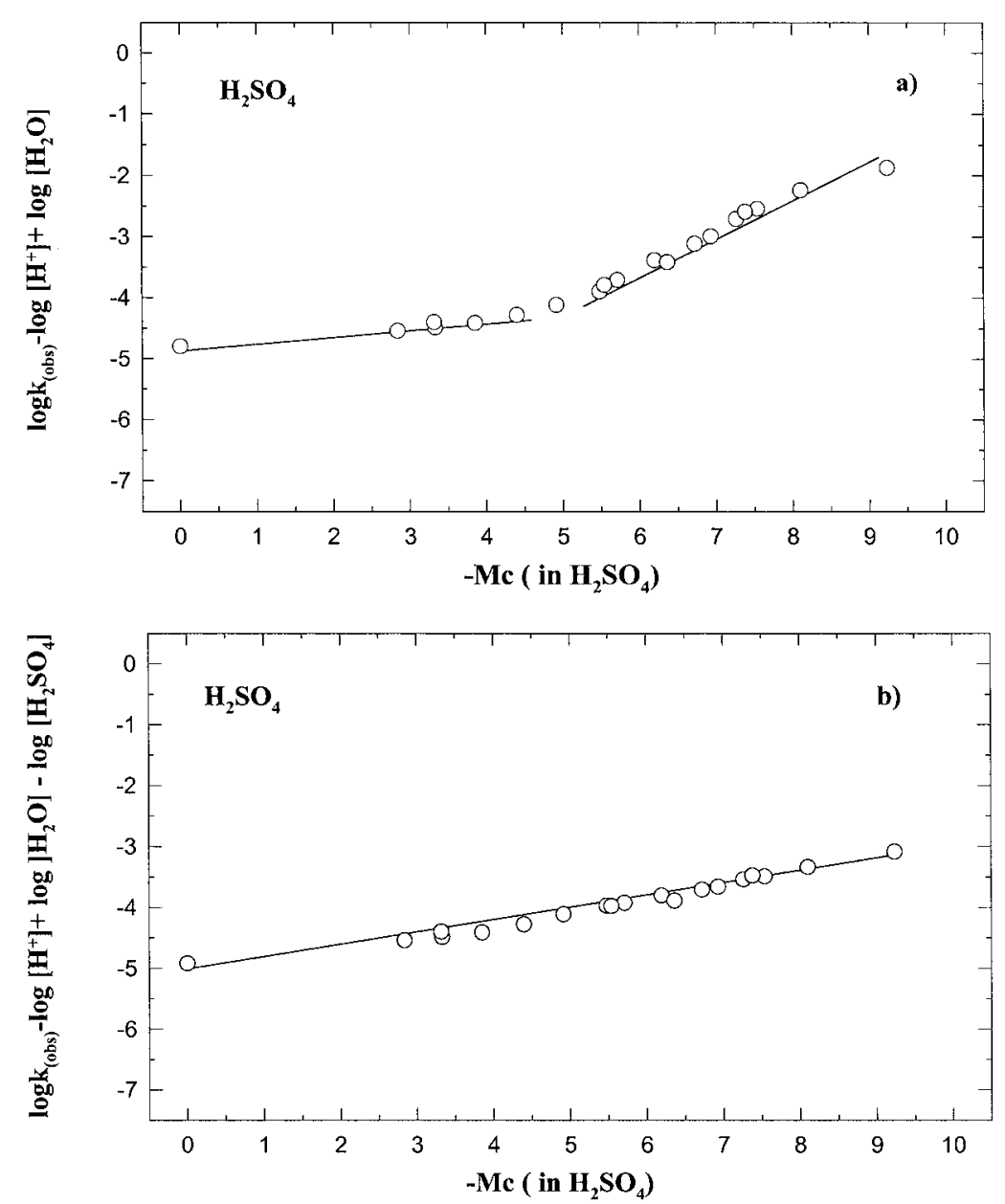

Figure 3 Beckmann rearrangement of 2,4,6-trimethylacetophenone oxime in $\mathrm{H}_{2} \mathrm{SO}_{4}$ (range 52-98 wt $\%$ ) at $25^{\circ} \mathrm{C}$ : a) $\mathrm{Plot}$ of $\left\{\log k_{\mathrm{obs}}-\log \left[\mathrm{H}^{+}\right]+\log \left[\mathrm{H}_{2} \mathrm{O}\right]\right\}$ vs Mc. b) Plot of $\left\{\log k_{\mathrm{obs}}-\log \left[\mathrm{H}^{+}\right]+\log \left[\mathrm{H}_{2} \mathrm{O}\right]-\log \left[\mathrm{H}_{2} \mathrm{SO}_{4}\right]\right\}$ vs Mc; intercept $=-4.8$, slope $=0.18$. Values of $\log k_{\mathrm{obs}}$ for the formation of intermediate from Ref. [7] and present work. Values of $\mathrm{Mc}$ and $\log \left[\mathrm{H}^{+}\right]$ from Ref. [13].

\section{Spectral Analysis}

The rearrangement of 2,4,6-trimethyl- and unsubstituted acetophenone oximes in concentrated acid solutions was analyzed by Raman and NMR measurements on the attempt to identify molecular and ionic species present in the systems under investigation.

In Fig. 4 the Raman spectra of TMTOX obtained in chloroform and in sulfuric acid at $96 \mathrm{wt} \%$ are reported. The comparison shows that in sulfuric acid the new bands at 2405, 2367, and $2329 \mathrm{~cm}^{-1}$ are observed which are independent of time but disappear by addition of water. The spectral trend and the spectral region are very similar to those reported in the infrared spectrum of dimethylnitrilium ion for which the stretching frequency of $[-\mathrm{C} \equiv \mathrm{N}-]^{+}$at 2416 $\mathrm{cm}^{-1}$ has been assigned [23]. On the contrary, the
Raman spectra of unsubstituted acetophenone oxime in analogous solvents exhibit only a spectral modification of the bands in the region between 1450$1680 \mathrm{~cm}^{-1}$.

In Table II and in Fig. 5 the results obtained by multinuclear NMR measurements are given. The first species observed at very short time when acetophenone oxime (IV) is dissolved in different concentrated acid solutions at $25^{\circ} \mathrm{C}$ is the corresponding $\mathrm{N}$ protonated form $(\mathrm{V})$. This species can be assigned very easily by the ${ }^{15} \mathrm{~N}$-proton coupled NMR spectra where a doublet has been observed. The values (referred to aqueous solution of $\mathrm{NH}_{4} \mathrm{NO}_{3}$ ) are centered at: $211.25 \mathrm{ppm}\left({ }^{1} J_{\mathrm{NH}}=108.18 \mathrm{~Hz}\right)$ in $\mathrm{CF}_{3} \mathrm{SO}_{3} \mathrm{H}$, at $212.39 \mathrm{ppm}\left({ }^{1} J_{\mathrm{NH}}=111.70 \mathrm{~Hz}\right)$ in $\mathrm{H}_{2} \mathrm{SO}_{4}$, and at $217.09 \mathrm{ppm}\left({ }^{1} J_{\mathrm{NH}}=103.89 \mathrm{~Hz}\right)$ in $\mathrm{CH}_{3} \mathrm{SO}_{3} \mathrm{H}$ and are consistent with ${ }^{15} \mathrm{~N}$ NMR data already reported [24]. 
Table III Beckmann Rearrangement of Some Oximes in Aqueous Strong Acids

\begin{tabular}{|c|c|c|c|c|c|}
\hline Oximes & $T\left({ }^{\circ} \mathrm{C}\right)$ & Acid & wt $\%$ & $\log k^{\mathrm{o} a, b}$ & $\sigma^{c}$ \\
\hline 2,4,6-Trimethyl-acetophenone- & 25 & $\mathrm{CF}_{3} \mathrm{SO}_{3} \mathrm{H}$ & $(69-100)^{d}$ & -4.8 & \\
\hline 2,4,6-Trimethyl-acetophenone- & 25 & $\mathrm{CH}_{3} \mathrm{SO}_{3} \mathrm{H}$ & $(90-100)^{d}$ & -4.8 & \\
\hline 2,4,6-Trimethyl-acetophenone- & 25 & $\mathrm{HClO}_{4}$ & $(52-72)^{e}$ & -4.8 & \\
\hline 2,4,6-Trimethyl-acetophenone- & 25 & $\mathrm{H}_{2} \mathrm{SO}_{4}$ & $(55-98)^{d, e}$ & -4.8 & \\
\hline 4-OMe-acetophenone- & 80 & $\mathrm{H}_{2} \mathrm{SO}_{4}$ & $(70-98)^{e}$ & -4.5 & -0.27 \\
\hline 4-Me-acetophenone- & 80 & $\mathrm{H}_{2} \mathrm{SO}_{4}$ & $(70-98)^{e}$ & -4.9 & -0.17 \\
\hline Acetophenone- & 80 & $\mathrm{CF}_{3} \mathrm{SO}_{3} \mathrm{H}$ & $(94-100)^{f}$ & -5.3 & 0.00 \\
\hline Acetophenone- & 80 & $\mathrm{H}_{2} \mathrm{SO}_{4}$ & $(70-98)^{e}$ & -5.3 & 0.00 \\
\hline 3-F-acetophenone- & 80 & $\mathrm{H}_{2} \mathrm{SO}_{4}$ & $(85-98)^{e}$ & -6.5 & 0.337 \\
\hline 4- $\mathrm{NO}_{2}$-acetophenone- & 80 & $\mathrm{H}_{2} \mathrm{SO}_{4}$ & $(85-98)^{e}$ & -7.9 & 0.778 \\
\hline Cyclohexanone- & 25 & $\mathrm{H}_{2} \mathrm{SO}_{4}$ & $(82-99)^{g}$ & -8.1 & \\
\hline Cyclohexanone- & 60 & $\mathrm{H}_{2} \mathrm{SO}_{4}$ & $(82-99)^{g}$ & -6.1 & \\
\hline Cyclohexanone- & 60 & $\mathrm{H}_{2} \mathrm{SO}_{4}$ & $(89-99)^{h}$ & -6.1 & \\
\hline Cyclohexanone- & 90 & $\mathrm{HClO}_{4}$ & $(47-60)^{h}$ & -4.6 & \\
\hline Cyclohexanone- & 90 & $\mathrm{H}_{2} \mathrm{SO}_{4}$ & $(48-80)^{h}$ & -4.6 & \\
\hline Cyclohexanone- & 90 & $\mathrm{H}_{2} \mathrm{SO}_{4}$ & $(82-99)^{g}$ & -4.6 & \\
\hline
\end{tabular}

${ }^{a} \log k^{0}=$ intercept of the plot $\left\{\log k_{(\mathrm{obs})}-\log \left[\mathrm{H}^{+}\right]+\log \left[\mathrm{H}_{2} \mathrm{O}\right]\right\}$ vs Mc (for experimental data in monoprotic acids and in sulfuric acid $<80$ $\mathrm{wt} \%)$.

${ }^{b} \log k^{0}=$ intercept of the plot $\left\{\log k_{\text {(obs) }}-\log \left[\mathrm{H}^{+}\right]+\log \left[\mathrm{H}_{2} \mathrm{O}\right]+\log \left[\mathrm{H}_{2} \mathrm{SO}_{4}\right]\right\}$ vs Mc (for experimental data in sulfuric acid $>80 \mathrm{wt} \%$ ).

${ }^{c}$ Hammett $\sigma$ constants of substituents.

${ }^{d} \log k_{(\mathrm{obs})}$ from present work (see Table I).

${ }^{e} \log k_{\text {(obs) }}$ from Ref. [7].

${ }^{f} \log k_{\text {(obs) }}$ of acetophenone oxime in $\mathrm{CF}_{3} \mathrm{SO}_{3} \mathrm{H}$ at $80^{\circ} \mathrm{C}$ from present work: (wt $\%$ and $\log k_{(\mathrm{obs})}$ values are: $94.05 \%=-5.13 ; 97.78 \%=$ $-4.83 ; 98.35 \%=-4.70 ; 100 \%=-4.60)$.

${ }^{g} \log k_{(\text {obs })}$ from Ref. [6].

${ }^{h} \log k_{\text {(obs) }}$ from Ref. [3].

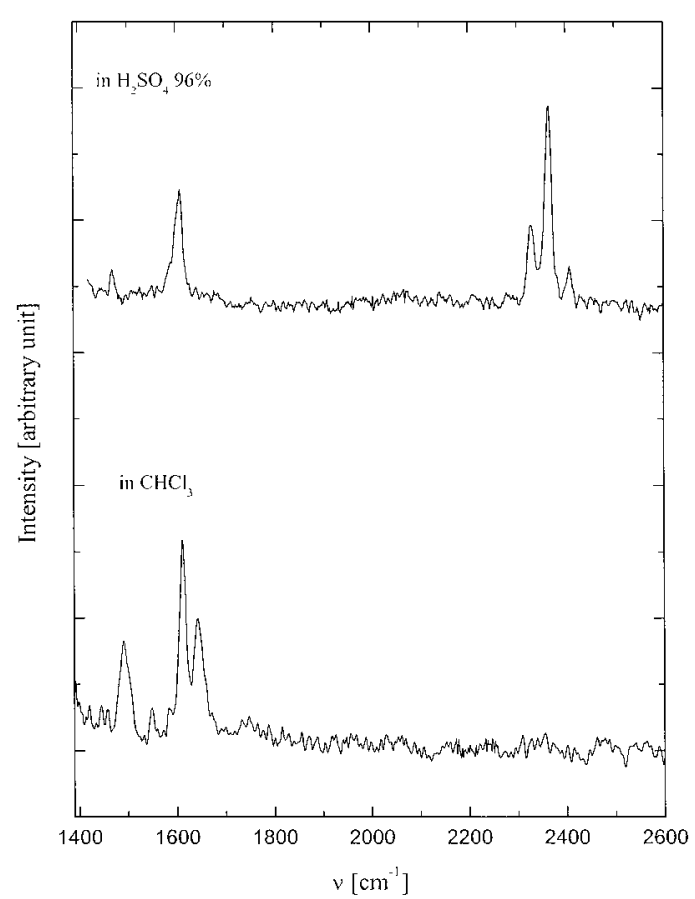

Figure 4 Raman spectra of 2,4,6-trimethylacetophenone oxime in $\mathrm{CHCl}_{3}$ and in $\mathrm{H}_{2} \mathrm{SO}_{4}(96 \mathrm{wt} \%)$ at $25^{\circ} \mathrm{C}$. The spectrum in $\mathrm{H}_{2} \mathrm{SO}_{4}$ has been assigned to $N$-arylnitrilium ion $\left[\mathrm{Me}-\mathrm{C} \equiv \mathrm{N}-\mathrm{C}_{6} \mathrm{H}_{3} \mathrm{Me}_{3}\right]^{+}$(see species III of Table IIb).
The N-protonation of the TMTOX (II) has been confirmed indirectly by comparing the ${ }^{1} \mathrm{H}$ NMR and the ${ }^{13} \mathrm{C}$ NMR spectra with the analogous ones of $\mathrm{N}$-protonated acetophenone oxime (V).

In the ${ }^{13} \mathrm{C}$ NMR spectrum, for instance, a $23 \mathrm{ppm}$ ca. downfield shift compared to unprotonated form has been observed for both the $\mathrm{C}_{\delta}$ peaks of the protonated species (see Table II). In the ${ }^{1} \mathrm{H}$ NMR spectra, the peak related to the proton of $\mathrm{N}-\mathrm{H}$ group falls between 11.5 and $12.5 \mathrm{ppm}$, depending on the acid.

In triflic and in sulfuric acids, a spectral change of TMTOX with time is observed due to rearrangement from the protonated form (II) to nitrilium ion (III). The evidence of (III) stands mostly in the ${ }^{13} \mathrm{C}$ NMR spectra since a typical value for the carbon of a $\mathrm{C} \equiv \mathrm{N}$ group has been observed [25].

Indeed, the $\mathrm{C}_{\delta}$ peak has now been found at about 120 ppm. Moreover, the $\mathrm{C}_{\beta}$ directly bonded to $\mathrm{C}_{\delta}$ shifts toward very high fields (up to $4 \mathrm{ppm}$ ca.) due to the strong and well known anisotropic effect of a $\mathrm{CN}$ triple bond [25]. Also $\mathrm{C}_{1}$ feels this effect. $\mathrm{A}^{15} \mathrm{~N}$-proton coupled NMR spectrum of TMTOX related to the ion (III) shows a sharp singlet at $144.63 \mathrm{ppm}$ in triflic acid and at $144.33 \mathrm{ppm}$ in sulfuric acid (referred to aqueous $\mathrm{NH}_{4} \mathrm{NO}_{3}$ ). 

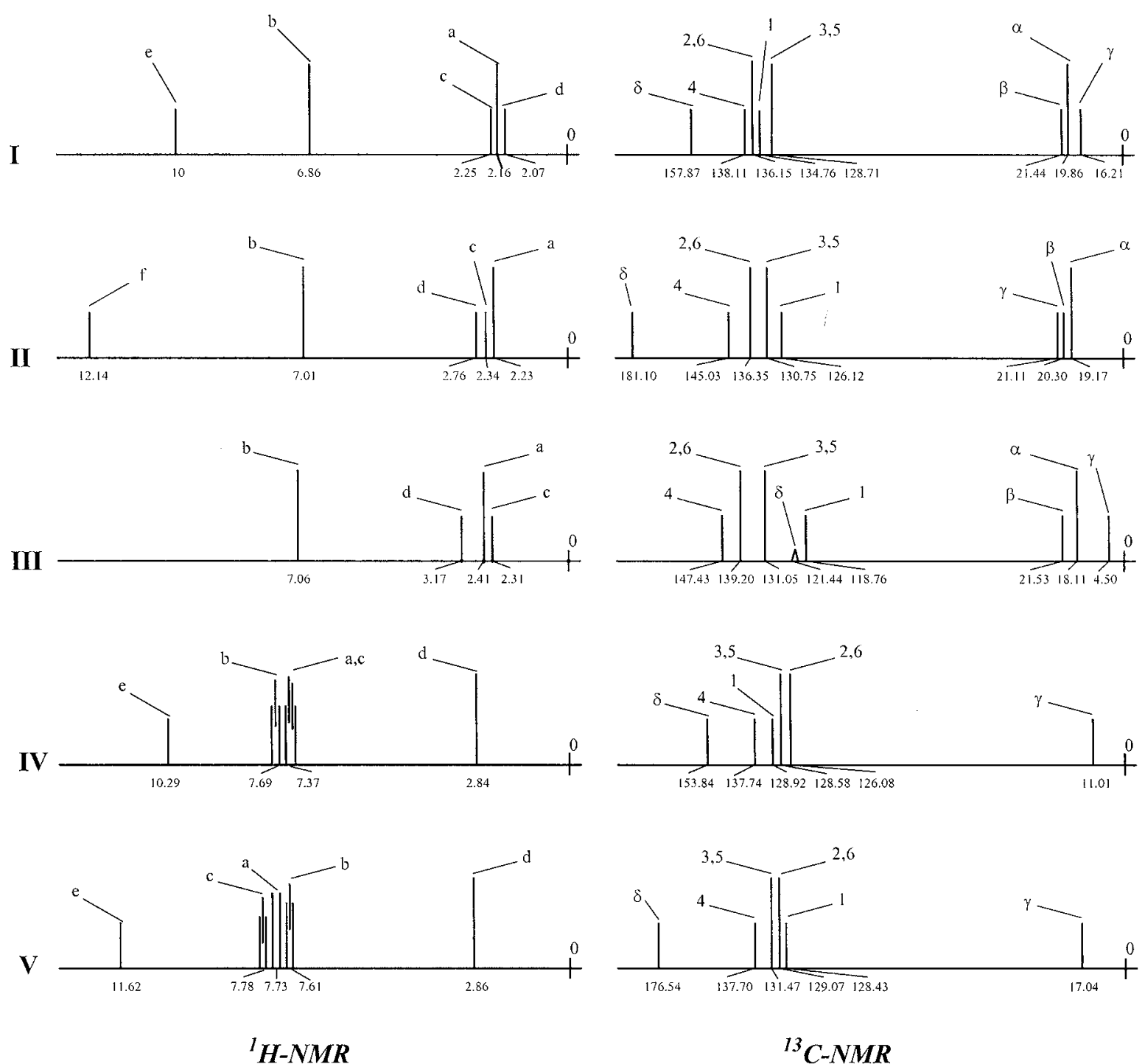

${ }^{I} H-N M R$

${ }^{13} \mathrm{C}-\mathrm{NMR}$

Figure $5{ }^{1} \mathrm{H}$ NMR and ${ }^{13} \mathrm{C}$ NMR spectra of 2,4,6-trimethyl- and acetophenone oximes: 2,4,6-trimethylacetophenone oxime: species (I) in deuterated acetone, (II) and (III) in $\mathrm{CF}_{3} \mathrm{SO}_{3} \mathrm{H}$; Acetophenone oxime: species (IV) in deuterated acetone, (V) in $\mathrm{CF}_{3} \mathrm{SO}_{3} \mathrm{H}$. For details of the species see Table II.

\section{Key Points of Rearrangement}

The results reported in the previous sections suggest some aspects of the rearrangement of particular interest:

a. The new results are consistent with the involvement of a protonation-dehydration of the starting ion $[>\mathrm{C}=\mathrm{NH}-\mathrm{OH}]^{+}$as key point of the rearrangement and with an internal electrophilic substitution by the resulting "nitrogen unstable species" toward a nucleophilic fragment of the oxime. The process appears to be very similar to nitration of aromatic compounds carried out in concentrated strong acids where the reaction exhibits rate profiles proportional to substituent effects in the aromatic ring and to concentration of the electrophilic species, the latter formed by the protonation-dehydration equilibrium of $\mathrm{HNO}_{3}$ to $\mathrm{NO}_{2}{ }^{+}$.

b. Sulfuric, perchloric, triflic, and methanesulfonic acids exhibit a very similar catalytic effect, except in sulfuric acid $>80 \%$ where the $\left[\mathrm{H}_{2} \mathrm{SO}_{4}\right]$ molecular species is occurring. In this range the large increase in rates is in agreement with "an active solvent participation as catalyst" as already suggested by Nguyen using a theoretical model for solvent [26]. Unfortunately, the properties of very concentrated acid solutions, characterized by complex ionizations and by the appearence of new species $\left(\mathrm{as}_{3} \mathrm{SO}_{4}{ }^{+}\right.$, 
$\mathrm{SO}_{3}, \mathrm{H}_{2} \mathrm{~S}_{2} \mathrm{O}_{7}$ ) do not allow univocal explanations of the mechanistic path of the solvent. Nevertheless, in the range where $\left[\mathrm{H}_{2} \mathrm{SO}_{4}\right]$ molecular species are available, solute-solvent interactions by the $-\mathrm{OH}$ groups and a proton-jump conduction mechanism would be expected to be reasonably effective.

c. New and old $[7,24]$ spectroscopic measurements show that the nitrilium ion is an intermediate of the reaction whose stability as "long-lived free species" is determined from the structure of the starting oxime and from the solute-solvent interactions. For instance, the high slopes observed for the destruction of the intermediate of TMTOX in perchloric, triflic, and sulfuric acids suggest that interactions between ionic species [27] giving ion pairs \{i.e. $\left[\mathrm{Me}-\mathrm{C} \equiv \mathrm{N}-\mathrm{C}_{6} \mathrm{H}_{3} \mathrm{Me}_{3}\right]^{+} \mathrm{X}^{-},\left(\mathrm{X}^{-}=\right.$ $\left.\left.\mathrm{ClO}_{4}{ }^{-}, \mathrm{CF}_{3} \mathrm{SO}_{3}{ }^{-}, \mathrm{HSO}_{4}{ }^{-}\right)\right\}$are occurring, whose stability increases with increase in the acid concentration. Analogously, the ion pairs formed between the starting oxime and the solvent (i.e. $[>\mathrm{C}=\mathrm{NH}-\mathrm{OH}]^{+} \mathrm{CF}_{3} \mathrm{SO}_{3}{ }^{-}$) could decrease the reaction rates observed in $\mathrm{CF}_{3} \mathrm{SO}_{3} \mathrm{H}$ above $90 \mathrm{wt} \%$ (see Fig. 1), where $\left[\mathrm{CF}_{3} \mathrm{SO}_{3}{ }^{-} \mathrm{H}_{3} \mathrm{O}^{+}\right]$species have also been detected [9]. As a matter of fact two acids with different acid strength as $\mathrm{CF}_{3} \mathrm{SO}_{3} \mathrm{H}$ and $\mathrm{CH}_{3} \mathrm{SO}_{3} \mathrm{H}$ appear to be equally effective on the comparison of reaction rates at high acid concentrations (see Table I).

The new results are consistent with the view that the catalytic trend of sulfuric acid and the interactions between the ionic species are very important experimental observations to be taken into account when an extension of the Beckmann rearrangement over solid acid catalysts is attempted.

\section{BIBLIOGRAPHY}

1. March, J. Advanced Organic Chemistry: Reaction, Mechanisms and Structure, 3rd ed.; Wiley: New York, 1985; p. 987.

2. Liler, M. Reaction Mechanisms in Sulphuric Acid; Academic Press: London, 1971.
3. Ogata, Y.; Okano, M.; Matsumoto, K. J Am Chem Soc $1955,77,4643$.

4. Greer, F.; Pearson, D. E. J Am Chem Soc 1955, 77, 6649.

5. McNulty, P. J.; Pearson, D. E. J Am Chem Soc 1959, 81, 612.

6. Vinnik, M. I.; Zarakhani, N. G. Russ Chem Rev (Eng. Trans.) 1967, 36, 51.

7. Gregory, B. J.; Moodie, R. B.; Schofield, K. J Chem Soc (B) 1970,338 .

8. Kim, S. G.; Kawakami, T.; Ando, T.; Yukawa, Y. Bull Chem Soc Japan 1979, 52, 1115.

9. Sampoli, M.; Marziano, N. C.; Tortato, C. J Phys Chem 1989, 93, 7252.

10. Marziano, N. C.; Tortato, C.; Bertani, R. J Chem Soc, Perkin Trans 2 1992, 955.

11. Marziano, N. C.; Tomasin, A.; Tortato, C. Org React (Estonia) 1996, 30, 29.

12. Marziano, N. C.; Tomasin, A.; Tortato, C. Org React (Estonia) 1996, 30, 39.

13. Marziano, N. C.; Tomasin, A.; Tortato, C.; Isandelli, P. J Chem Soc, Perkin Trans 2 1998, 2535.

14. Marziano, N. C.; Tomasin, A.; Tortato, C.; Zaldivar, J. M. J Chem Soc, Perkin Trans 2 1998, 1973.

15. Marziano, N. C.; Tortato, C.; Ronchin, L.; Bianchi, C. Catal Lett 1998, 56, 159.

16. Marziano, N. C.; Tortato, C.; Ronchin, L.; Bianchi, C. Catal Lett 2000, 64, 15.

17. Marziano, N. C.; Ronchin, L.; Tortato, C.; Zingales, A.; Sheikh-Osman, A. A. J Mol Catal A: Chemical 2001, 174,265 .

18. Bax, A.; Subramian, S. J Magn Reson 1986, 67, 565.

19. Otting, G.; Wütrich, K. J Magn Reson 1988, 76, 569.

20. Drobny, G.; Pines, A.; Sinton, S.; Weitekamp, D.; Wemmer, D. Faraday Symp Chem Soc 1979, B33, 49.

21. Marziano, N. C.; Tortato, C.; Sampoli, M. J Chem Soc, Perkin Trans 2 1991, 423.

22. Marziano, N. C.; Tortato, C.; Ronchin, L.; Martini, F.; Bianchi, C. Catal Lett 1999, 58, 81.

23. Turrell, G. C.; Gordon, J. E. J Chem Phys 1959, 30, 895.

24. Olah, G. A.; Kiovsky, T. E. J Am Chem Soc 1968, 90, 4666.

25. Lalinowski, H.O.; Berger, S.; Braun, S. Carbon-13 NMR Spectroscopy; Wiley: Chichester, 1988.

26. Nguyen, M. T.; Raspoet, G.; Vanquickenborne, L. G. J Chem Soc, Perkin Trans 1997, 2, 821.

27. Reichardt, C. Solvent Effects in Organic Chemistry, Verlag Chemie: New York, 1979. 